\title{
BMJ Open Association between obesity and chronic rhinosinusitis with nasal polyps: a national population- based study
}

\author{
Jae-Sung Nam (D) , ${ }^{1}$ Yun Ho Roh, ${ }^{2}$ Wasan Almazouq Fahad, ${ }^{3}$ Hae-Eun Noh, ${ }^{1}$ \\ Jong-Gyun Ha, ${ }^{4}$ Joo-Heon Yoon, ${ }^{1,5,6}$ Chang-Hoon Kim, ${ }^{1,5,6,7}$ Hyung-Ju Cho (D) ${ }^{1,5,6}$
}

To cite: Nam J-S, Roh YH, Fahad WA, et al. Association between obesity and chronic rhinosinusitis with nasal polyps: a national populationbased study. BMJ Open 2021;11:e047230. doi:10.1136/ bmjopen-2020-047230

- Prepublication history for this paper is available online. To view these files, please visit the journal online (http://dx.doi. org/10.1136/bmjopen-2020047230).

Received 24 November 2020 Revised 01 April 2021 Accepted 09 April 2021
Check for updates

(C) Author(s) (or their employer(s)) 2021. Re-use permitted under CC BY-NC. No commercial re-use. See rights and permissions. Published by BMJ.

For numbered affiliations see end of article.

Correspondence to Professor Hyung-Ju Cho; hyungjucho@yuhs.ac

\section{ABSTRACT}

Objectives We performed a cross-sectional analysis of data from the nationwide Korea National Health and Nutrition Examination Survey to evaluate the association between obesity and chronic rhinosinusitis with nasal polyps (CRSwNP) or without nasal polyp (CRSsNP).

Design Retrospective cross-sectional analysis of health survey data.

Setting Voluntary survey of representative South Korean populations.

Participants In total, 32384 individuals aged 19 years or older with available data on CRS and obesity were included.

Primary and secondary outcome measures Diagnosis of CRSwNP or CRSsNP was performed by trained otolaryngologists through sinus endoscopy and surveys of medical history. General and central obesity was diagnosed using body mass index (BMI) and waist circumference (WC), respectively.

Methods A multivariate logistic regression analysis was used to clarify the association between CRSwNP or CRSsNP and obesity according to BMI and WC. Non-obese individuals were recruited as controls.

Results The prevalence of CRSwNP was higher in the general (OR, 1.438; 95\% $\mathrm{Cl}, 1.170$ to $1.768 ; \mathrm{p}<0.001)$ and central (OR, 1.251; $95 \% \mathrm{Cl}, 1.031$ to $1.520 ; \mathrm{p}=0.033)$ obesity groups than in the control group. Prevalence of CRSsNP was not correlated with obesity. In a logistic regression analysis, olfactory dysfunction (OR, 1.329; 95\% $\mathrm{Cl}, 1.137$ to $1.553 ; \mathrm{p}<0.001)$ and purulent discharge $(0 \mathrm{R}$, 1.383; $95 \% \mathrm{Cl}, 1.193$ to $1.603 ; \mathrm{p}<0.001$ ) showed a higher incidence in the central obesity group than in the control group.

Conclusions We demonstrated an association between CRSwNP and general and central obesity. Further investigations on the mechanism underlying this correlation are necessary for an improved understanding of the pathogenesis of CRSwNP.

\section{INTRODUCTION}

Obesity is a rapidly increasing global health problem. Over 1.9 billion people are classified as overweight and over 650 million are categorised as obese, globally. ${ }^{1}$ Diseases related to obesity include asthma, cardiovascular
Strengths and limitations of this study

- This study used data from the Korea National Health and Nutrition Examination Survey, a representative national population-based study in Korea.

- The study sample included a large number of participants ( $\mathrm{N}=32$ 384) who had a wide age range (19-86 years).

- This study examined general and central obesity, which are important public health concerns.

- The association between chronic rhinosinusitis and obesity was explored after adjusting for age, sex, diagnosis of hypertension and other relevant clinical characteristics.

- The causal relationship between obesity and chronic rhinosinusitis phenotypes was not assessed in this study.

diseases and diabetes mellitus. Certain types of cancers are also associated with obesity due to chronic inflammation. ${ }^{23}$ There have been reports suggesting that obesity can potentially result in chronic inflammatory diseases. ${ }^{4}$ However, controversies remain about the effect of obesity in sinonasal inflammatory diseases. $^{56}$

Chronic rhinosinusitis (CRS) is defined as persistent inflammation of the sinonasal mucosa due to multifactorial causes. ${ }^{7}$ Staphylococcus aureus or Alternaria fungi have been reported as critical agents for CRS, ${ }^{8}$ and antibody deficiencies in primary immunodeficiencies may predispose certain patients to recurrent sinus infections. ${ }^{9}$

CRS is categorised as CRS with nasal polyps (CRSwNP) and CRS without nasal polyps (CRSsNP) based on the sinus endoscopy. ${ }^{10}$ CRSwNP is typically characterised as a type 2 inflammatory response, exhibiting enhanced tissue eosinophilia and higher levels of eosinophilic granule protein, ${ }^{11} 12$ eosinophil chemotactic proteins, interleukin (IL) -5 and 
IL-13. ${ }^{13} 14$ In general, patients with CRSwNP have more severe nasal obstruction than patients with CRSsNP, and effective medical treatments for patients with CRSwNP are limited. ${ }^{15}{ }^{16}$ In addition, patients with CRSwNP have a significantly lower health-related quality of life compared with healthy controls. ${ }^{17}$

Several studies have reported that obesity is a potential chronic inflammatory condition and leads to chronic systemic inflammation. ${ }^{418}$ However, to our knowledge, no previous studies have reported the association of CRSwNP with general and central obesity under the influence of various confounding factors in large nationwide studies. As a representative measure of obesity, body mass index (BMI) is the most widely used parameter for general obesity diagnosis and is correlated with various chronic diseases and mortality risk. However, a limitation of BMI is that it does not represent the body fat distribution. ${ }^{19}$ Waist circumference (WC) has been commonly used as a simple and clinically applicable method to evaluate central obesity. ${ }^{20}$ Thus, using both of these measurements is appropriate when investigating the relationship between general and central obesity and CRSwNP. In this study, we aimed to investigate this association using data retrieved from the Korea National Health and Nutrition Examination Survey (KNHANES), with subgroup analysis and stratification for major confounding factors.

\section{MATERIALS AND METHODS}

\section{Study design and population}

The data for the study were collected by the KNHANES between 2008 and 2012. The KNHANES was a national cross-sectional survey conducted by the Ministry of Health and Welfare of South Korea. Specially trained medical investigators used well-designed questionnaires to evaluate representative South Korean populations. The evaluation included physical examination, healthrelated surveys and nutritional status assessment. In the current study, 34670 participants aged $\geq 19$ years were included. After excluding 2286 participants with missing data on CRS or obesity, the data of 32384 participants were analysed. All eligible participants provided written informed consent. The study followed the Ethical Principles for Medical Research Involving Human Subjects based on the Declaration of Helsinki.

\section{General characteristics}

Of the total KNHANES study population, only the participants aged $\geq 19$ years were included in this study. Sociodemographic and economic variables of the participants were acquired with a self-reported questionnaire, which collected information on cigarette smoking habits, household income, alcohol consumption, education level and region of residence. Alcohol drinkers were categorised as heavy (>30 g/day), mild (1-30 g/day) and non-drinkers. Smokers were categorised as non-smokers or ex-smokers and current smokers. Education level was categorised as graduation from high school ( $\geq 13$ years) or not.
Household income was classified into quartiles by the number of family members, following recommendations of the WHO.

The medical evaluation included assessment of blood pressure, height, weight and WC. Hypertension was confirmed when the systolic or diastolic blood pressure measurements were repeatedly over 140/90 mm $\mathrm{Hg}$. Height $(\mathrm{cm})$ was measured using a stadiometer (Seca 225, Seca, Germany) while the participants had their upper back parallel to the wall, were facing forward and were without shoes. Weight $(\mathrm{kg})$ was measured by a digital medical weighing scale (GL-6000-20, G-Tech International, South Korea) with participants wearing light clothes. Results were recorded by trained examiners and presented up to the second decimal. The physical examination devices were replaced with recently calibrated devices once a year to maintain the accuracy of results. BMI was calculated by dividing the weight $(\mathrm{kg})$ by the squared height $\left(\mathrm{m}^{2}\right)$. WC was measured at the midpoint level between the costal margin and the iliac crest at the end of a normal expiration. Chronic diseases, such as stroke, bronchial asthma, allergic rhinitis, depression and pulmonary tuberculosis, previously diagnosed by a physician were also investigated throughout the survey.

\section{Diagnosis of CRSwNP and CRSsNP}

CRS was diagnosed by trained otolaryngologists using sinus endoscopy and surveys of medical histories following the European Position Paper on Rhinosinusitus and Nasal Polyps (EPOS) 2012 guidelines for epidemiological studies.

Each participant was evaluated by a single otolaryngologist, and overall, approximately 200 trained otolaryngologists were involved in the KNHANES. CRS was defined as inflammation of the nose and paranasal sinuses with the presence of two or more of the following symptoms for over 12 weeks: (1) nasal blockage/congestion/ obstruction; (2) sinonasal discharge; (3) facial pressure/ pain; and (4) reduction or loss of smell. ${ }^{21}$ An objective diagnosis of either CRSsNP or CRSwNP was made using sinus endoscopy. The participants' socio-demographics, general health characteristics and comorbidities were compared with determine the risk factors for CRS.

\section{Definition of general obesity according to the BMI}

The WHO Regional Office for the Western Pacific Region has announced the following BMI standards: normal, $18.5-22.9 \mathrm{~kg} / \mathrm{m}^{2}$; overweight, $23-24.9 \mathrm{~kg} / \mathrm{m}^{2}$; and obese $\geq 25 \mathrm{~kg} / \mathrm{m}^{2}{ }^{22}$ This definition for obesity was followed by the Korean Society for the Study of Obesity and was used in the present study to define general obesity. ${ }^{23}$

\section{Definition of central obesity according to the WC}

The Korean Society for the Study of Obesity recommends that the WC cut-off level for diagnosing central obesity be $90 \mathrm{~cm}$ for men and $85 \mathrm{~cm}$ for women aged $\geq 19$ years. These cut-off values were defined by receiver operating characteristics curve analysis, based on the representative 
sample data acquired during the KNHANES in $1998 .^{24}$ The same standards were applied in this study to define central obesity in the participants.

\section{Statistical analysis}

All statistical analyses were conducted with the SAS software, V.9.4. Differences with $\mathrm{p}$ values below 0.05 were considered statistically significant. SAS/STAT survey analyses were conducted because the KNHANES had applied a stratified cluster sampling method when selecting participants from 2008 to 2012. Descriptive statistics have been presented as means (SEs) for categorical variables and weighted percentages (SEs) for continuous variables and frequencies. A Pearson's $\chi^{2}$ test was used to compare categorical variables, and an independent samples t-test was used to compare continuous variables. The SAS PROC SURVEYREG was used to analyse continuous variables, and the PROC SURVEYFREQ was used for categorical variables. A multiple logistic regression analysis was conducted by the SAS PROC SURVEYLOGISTIC, after adjusting for multiple variables, to clarify the association between CRS phenotypes and general and central obesity (BMI-related and WC-related, respectively). Models were run after adding age and sex for model 1; smoking and severe drinking for model 2; and family income, residence, hypertension, stroke, bronchial asthma, influenza vaccination, allergic rhinitis, and pulmonary tuberculosis for model 3.

\section{Patient and public involvement}

The study population was not involved in the development of the research questionnaires, in the analysis or in drawing conclusions from the results.

\section{RESULTS}

\section{Demographics of the study participants}

Among the total participants, 32384 were categorised as normal, overweight or obese, according to BMI. The demographic and clinical characteristics of these participants are presented in table 1 . The mean age was 42.65 (0.23) years for participants with normal weight, 47.29 (0.24) years for overweight and $47.05(0.22)$ years for obese participants. Factors with significant differences among the groups were age, sex, smoking status, severe drinking, family income, residence, hypertension, depression, bronchial asthma, influenza vaccination, allergic rhinitis and stroke. Using the WC standard, 23260 participants were considered normal and 8690 participants were diagnosed with central obesity. Table 2 shows the clinical characteristics of the participants according to the presence of WC-based central obesity.

\section{Prevalence of CRS in relation to general and central obesity}

The overall prevalence of CRS in the participants categorised by BMI was $5.81(0.31) \%$ in the normal weight group, $5.91(0.37) \%$ in the overweight group and $6.70(0.36) \%$ in the obese group. The normal and obese groups differed significantly when assessed by regression analysis (OR, 1.164; 95\% CI, 1.009 to 1.342; $\mathrm{p}=0.036)$. The prevalence of CRSwNP in the normal and obese groups was $2.20(0.16) \%$ and $3.43(0.25) \%$, respectively; while that of CRSsNP was $3.36(0.21) \%$ and $3.50(0.29) \%$, respectively.

Among the groups categorised by WC, the overall prevalence of CRS was $5.89(0.24) \%$ in the normal group and $6.81(0.39) \%$ in the centrally obese group. The prevalence of CRSwNP was $3.44(0.26 \%)$ in the

Table 1 Participants characteristics according to body mass index-based general obesity

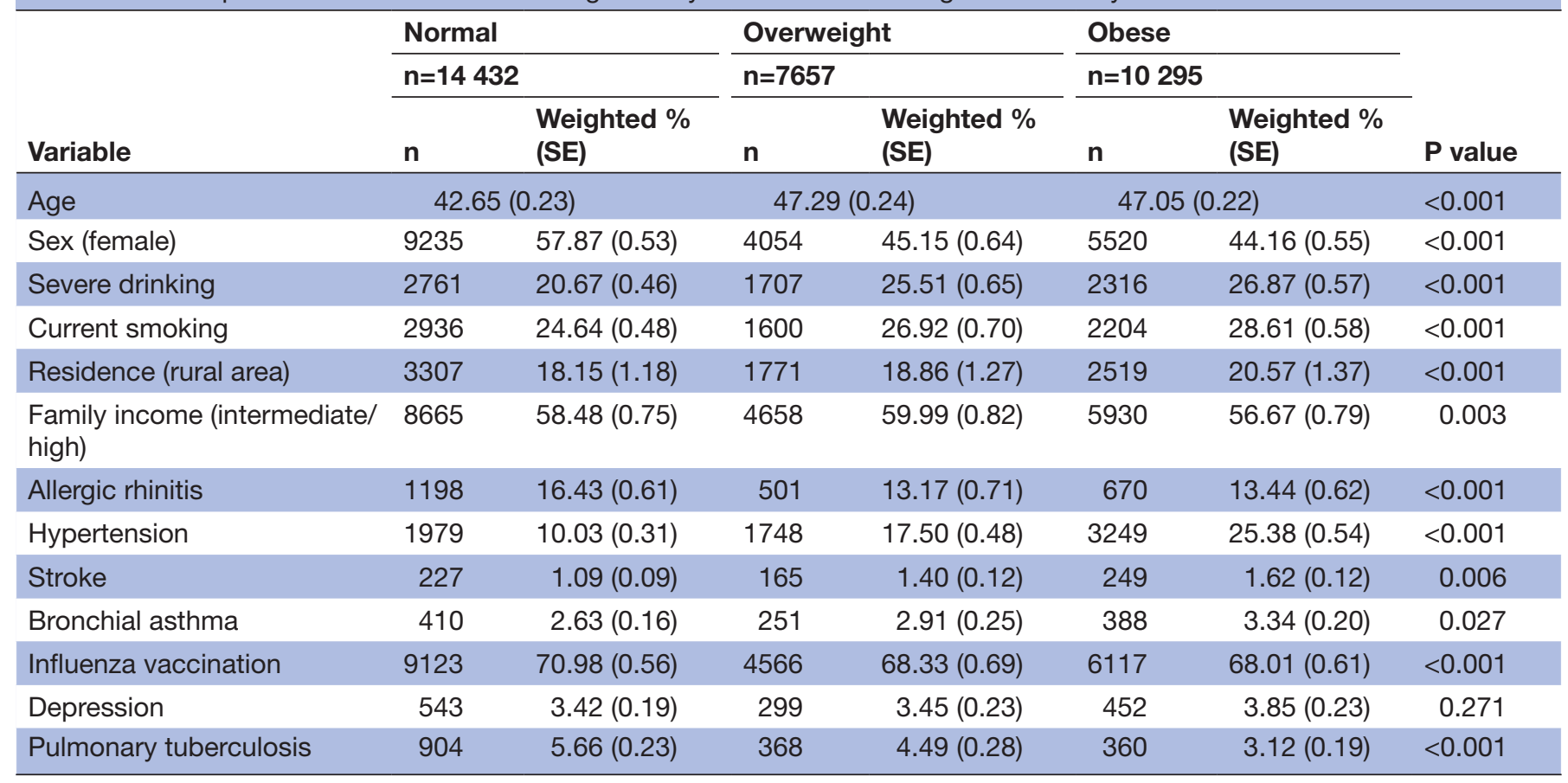


Table 2 Participants characteristics according to waist circumference-based central obesity

\begin{tabular}{|c|c|c|c|c|c|}
\hline \multirow[b]{3}{*}{ Variable } & \multicolumn{2}{|c|}{ Normal } & \multicolumn{2}{|c|}{ Obese } & \multirow[b]{3}{*}{$P$ value } \\
\hline & \multicolumn{2}{|c|}{$n=23260$} & \multicolumn{2}{|c|}{$\mathrm{n}=8690$} & \\
\hline & $\mathbf{n}$ & Weighted \% (SE) & $\mathbf{n}$ & Weighted \% (SE) & \\
\hline Age & \multicolumn{2}{|c|}{$43.17(0.21)$} & \multicolumn{2}{|c|}{$50.37(0.29)$} & $<0.001$ \\
\hline Sex (female) & 11315 & $51.02(0.39)$ & 4124 & $49.04(0.68)$ & 0.023 \\
\hline Severe drinking & 4167 & $23.19(0.41)$ & 1563 & $25.99(0.65)$ & $<0.001$ \\
\hline Current smoking & 4318 & $26.81(0.44)$ & 1419 & $26.85(0.68)$ & 0.956 \\
\hline Residence (rural area) & 4418 & $17.74(1.29)$ & 1989 & $23.33(1.71)$ & $<0.001$ \\
\hline Family income (intermediate/high) & 11754 & $58.92(0.71)$ & 4086 & $57.61(0.91)$ & 0.154 \\
\hline Allergic rhinitis & 1890 & $15.62(0.49)$ & 486 & $11.86(0.64)$ & $<0.001$ \\
\hline Hypertension & 3832 & $12.10(0.28)$ & 3183 & $30.73(0.65)$ & $<0.001$ \\
\hline Stroke & 386 & $1.10(0.07)$ & 262 & $2.06(0.15)$ & $<0.001$ \\
\hline Bronchial asthma & 672 & $2.62(0.13)$ & 388 & $3.95(0.25)$ & $<0.001$ \\
\hline Depression & 866 & $26.13(0.97)$ & 429 & $30.40(1.66)$ & 0.023 \\
\hline Pulmonary tuberculosis & 1288 & $4.87(0.17)$ & 351 & $3.66(0.22)$ & $<0.001$ \\
\hline
\end{tabular}

centrally obese group and $2.40(0.14) \%$ in the normal group. The prevalence of CRSsNP was $3.66(0.21) \%$ in the centrally obese group and $3.61(0.32) \%$ in the normal group (figure 1).

\section{Correlation between CRSwNP prevalence and general and} central obesity

Among the groups classified by the BMI, CRSwNP was more prevalent in the general obesity group than in the normal group (OR, 1.582; 95\% CI, 1.294 to 1.934; $\mathrm{p}<0.001$ ), but did not differ between the normal and overweight groups (OR, 1.120; 95\% CI, 0.894 to 1.404; $\mathrm{p}=0.324)$. Multivariate regression analysis was performed under various confounding factors with models 1,2 and 3, showing a higher prevalence of CRSwNP in the general obesity group than in the normal group (OR, $1.438 ; 95 \%$ CI, 1.170 to 1.768 ; $\mathrm{p}<0.001$ in model 3 ). When participants were classified by the WC, univariate logistic regression analysis showed that the prevalence of CRSwNP in the central obesity group was higher than in the normal group (OR, 1.447; 95\% CI, 1.208 to 1.733; $\mathrm{p}<0.001)$. Multivariate regression analysis using the three models resulted in a similar outcome (OR, 1.251; $95 \%$ CI, 1.031 to $1.502 ; \mathrm{p}=0.023$ in model 3) (table 3).

\section{Correlation between CRSsNP prevalence and general and central obesity}

The correlation between CRSsNP and obesity was investigated. We found no difference in CRSsNP prevalence between the overweight and normal groups (OR, 1.019; $95 \%$ CI, 0.864 to $1.203 ; \mathrm{p}=0.820$ ), but a significant difference was noted between general obesity and normal groups (OR, 1.164; 95\% CI, 1.009 to $1.342 ; \mathrm{p}=0.036$ ). Multivariate regression analysis with models 1, 2 and 3 found no difference in CRSsNP prevalence between the normal and overweight (OR, 0.986; 95\% CI, 0.832 to 1.169; $\mathrm{p}=0.872$ in model 3) or in the normal and obese (OR, $1.130 ; 95 \%$ CI, 0.975 to $1.310 ; \mathrm{p}=0.104$ in model
A

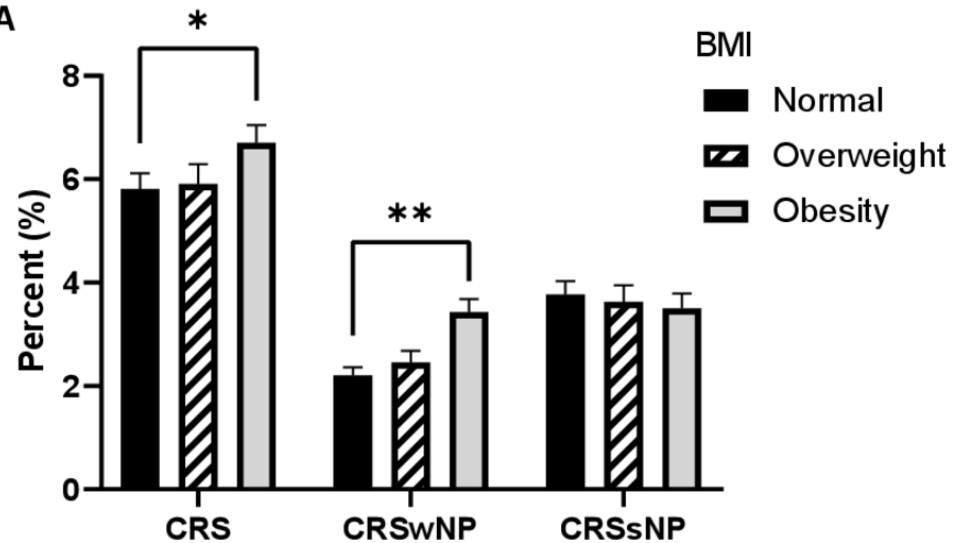

B

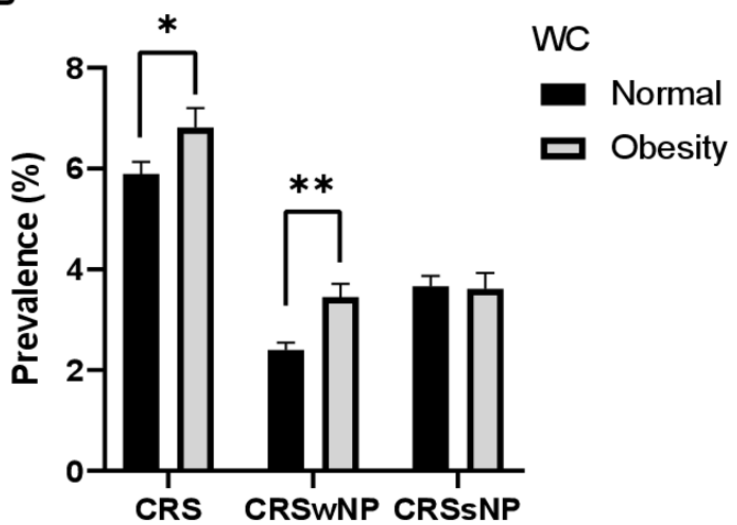

Figure 1 Prevalence of CRSwNP or CRSsNP according to the presence of obesity. (A) Prevalence of CRSwNP or CRSsNP according to general obesity. (B) Prevalence of CRSwNP or CRSsNP according to central obesity. BMI, body mass index; CRS, chronic rhinosinusitis; CRSsNP, CRS without nasal polyps; CRSwNP, CRS with nasal polyps; WC, waist circumference. ${ }^{*} p<0.05$, ${ }^{* *} \mathrm{p}<0.01$ (univariate logistic regression analysis). 
Table 3 Association between CRSwNP and obesity according to BMI and WC

\begin{tabular}{|c|c|c|c|}
\hline Model & Variable & OR $(95 \% \mathrm{Cl})$ & $P$ value \\
\hline \multirow[t]{2}{*}{ Unadjusted } & Overweight vs normal & $1.120(0.894$ to 1.404$)$ & 0.324 \\
\hline & Obesity vs normal & $1.582(1.294$ to 1.934$)$ & $0.000^{*}$ \\
\hline Model 1† & Obesity vs normal & 1.382 (1.129 to 1.693$)$ & $0.002^{*}$ \\
\hline Model 2ł & Overweight vs normal & $0.944(0.731$ to 1.220$)$ & 0.660 \\
\hline \multirow[t]{2}{*}{ Model 3§ } & Overweight vs normal & 0.968 (0.762 to 1.228$)$ & 0.787 \\
\hline & Obesity vs normal & 1.438 (1.170 to 1.768$)$ & $<0.001^{*}$ \\
\hline Unadjusted & Central obesity vs normal & 1.447 (1.208 to 1.733$)$ & $<0.001^{*}$ \\
\hline Model 1† & Central obesity vs normal & 1.226 (1.016 to 1.480$)$ & $0.033^{\star}$ \\
\hline Model 2ł & Central obesity vs normal & $1.257(1.021$ to 1.547$)$ & $0.030^{*}$ \\
\hline
\end{tabular}

${ }^{*}$ Differences with $\mathrm{p}<0.05$ were considered statistically significant.

†Model 1: adjusted for age and sex.

$\ddagger$ Model 2: adjusted for age, sex, current smoking and severe drinking.

§Model 3: adjusted for age, sex, current smoking, severe drinking, family income, residence, hypertension, stroke, bronchial asthma, influenza vaccination, allergic rhinitis and pulmonary tuberculosis.

BMI, body mass index; CRSwNP, chronic rhinosinusitis with nasal polyps; WC, waist circumference.

3) groups. When grouped by WC, the prevalence of CRSsNP in the central obesity group was higher than in the normal group on univariate analysis $(\mathrm{OR}, 1.168$; 95\% CI, 1.020 to $1.338 ; \mathrm{p}=0.024$ in model 3) but not in the multivariate regression analysis using the three models (OR, 1.144; $95 \%$ CI, 0.993 to $1.318 ; \mathrm{p}=0.063$ in model 3) (table 4).
Association of sinonasal symptoms with general and central obesity

In the logistic regression analysis, olfactory dysfunction (OR, 1.329; 95\% CI, 1.137 to 1.553 ; $\mathrm{p}<0.001$ ) and purulent discharge on sinus endoscopy (OR, $1.383 ; 95 \%$ CI, 1.193 to $1.603 ; \mathrm{p}<0.001$ ) showed a higher incidence rate in the central obesity group than in the normal group.

Table 4 Association between CRSsNP and obesity according to BMI and WC

\begin{tabular}{|c|c|c|c|}
\hline Model & Variable & OR $(95 \% \mathrm{Cl})$ & $P$ value \\
\hline Unadjusted & Obesity vs normal & 1.164 (1.009 to 1.342$)$ & $0.036^{*}$ \\
\hline Model 1† & Obesity vs normal & 1.091 (0.944 to 1.262$)$ & 0.237 \\
\hline Model 2‡ & Overweight vs normal & 0.960 (0.811 to 1.136$)$ & 0.634 \\
\hline \multirow[t]{2}{*}{ Model 3§ } & Overweight vs normal & $0.986(0.832$ to 1.169$)$ & 0.872 \\
\hline & Obesity vs normal & 1.130 (0.975 to 1.310$)$ & 0.104 \\
\hline Unadjusted & Central obesity vs normal & 1.168 (1.020 to 1.338$)$ & $0.024^{*}$ \\
\hline Model 1† & Central obesity vs normal & $1.124(0.980$ to 1.291$)$ & 0.095 \\
\hline
\end{tabular}

${ }^{*}$ Differences with $p<0.05$ were considered statistically significant.

†Model 1: adjusted for age and sex.

$\ddagger$ Model 2: adjusted for age, sex, current smoking and severe drinking.

§Model 3: adjusted for age, sex, current smoking, severe drinking, family income, residence, hypertension, stroke, bronchial asthma, influenza vaccination, allergic rhinitis and pulmonary tuberculosis.

BMI, body mass index; CRSsNP, chronic rhinosinusitis without nasal polyp; WC, waist circumference. 
Table 5 Sinonasal symptoms according to presence of general and central obesity

\begin{tabular}{|c|c|c|c|}
\hline Symptoms & Variable & OR $(95 \% \mathrm{Cl})$ & $P$ value \\
\hline \multirow[t]{2}{*}{ Rhinorrhoea/PND } & General obesity vs normal & $0.736(0.511$ to 1.058$)$ & 0.097 \\
\hline & Central obesity vs normal & 0.917 (0.763 to 1.101$)$ & 0.349 \\
\hline Nasal obstruction & Central obesity vs normal & 1.097 (0.928 to 1.297$)$ & 0.276 \\
\hline Olfactory dysfunction & General obesity vs normal & $1.011(0.722$ to 1.416$)$ & 0.948 \\
\hline \multirow[t]{2}{*}{ Daily life disability } & General obesity vs normal & 1.454 (1.083 to 1.952$)$ & $0.012^{*}$ \\
\hline & Central obesity vs normal & $1.121(0.948$ to 1.326$)$ & 0.179 \\
\hline \multirow[t]{2}{*}{ Pale mucosa } & General obesity vs normal & 0.746 (0.591 to 0.942$)$ & $0.013^{*}$ \\
\hline & Central obesity vs normal & 0.870 (0.760 to 0.996$)$ & $0.043^{*}$ \\
\hline Purulent discharge & General obesity vs normal & $1.400(0.987$ to 1.988$)$ & 0.059 \\
\hline
\end{tabular}

${ }^{*}$ Differences with $\mathrm{p}<0.05$ were considered statistically significant.

PND, postnasal drip; WC, waist circumference.

Daily life disability (OR, 1.454; 95\% CI, 1.083 to 1.952 ; $\mathrm{p}=0.012$ ) was more prevalent in the general obesity group than in the normal group. Pale nasal mucosa on sinus endoscopy was more prevalent in the normal group than in the central (OR, $0.870 ; 95 \% \mathrm{CI}, 0.760$ to $0.996 ; \mathrm{p}=0.043$ ) and general (OR, 0.746; 95\% CI, 0.591 to $0.942 ; \mathrm{p}=0.013$ ) obesity groups. The presence of rhinorrhoea/postnasal drip and nasal obstruction did not differ between the normal and obesity groups (table 5).

\section{DISCUSSION}

In the present study, the prevalence of CRSwNP was significantly higher in the BMI-based general obesity and WC-based central obesity groups compared with the normal group. The association between CRSsNP and either general or central obesity was not significant. In addition, common sinonasal symptoms seen in CRS such as purulent discharge and olfactory dysfunction were more frequent in the central obesity group.

Previous studies investigating the association between obesity and sinus infections have shown inconsistent results. Obesity was reported to not affect the severity of sinonasal diseases in patients with asthma. ${ }^{5}$ While childhood obesity was associated with the occurrence of acute otitis media, an association between obesity and allergic rhinitis or CRS was not observed. ${ }^{6}$ Other studies have shown that a high BMI was associated with the prevalence of CRS. ${ }^{25}{ }^{26}$ However, these studies did not classify the prevalence of CRS based on the presence of nasal polyps; therefore, the effect of adiposity on CRSwNP has not been determined.

In this study, the association between general obesity and CRSsNP was insignificant in contrast to that with CRSwNP, after adjusting for various confounding factors. This result reveals that factors related to general obesity might be closely related to the polypogenesis process in sinonasal inflammatory disease, the mechanism for which has not been fully identified yet. Inflammatory pathophysiological processes are associated with obesity and certain respiratory diseases. ${ }^{27}$ Several mechanisms involved in the contribution of obesity to asthma progression have been studied. The increased production of cytokines, adipocytokines, adiponectin and other mediators by the adipose tissue is considered to have important implications in immune responses. ${ }^{28} 29$ There are reports indicating that increased levels of inflammatory mediators ${ }^{30}$ and metabolic hormones ${ }^{31}$ could be the possible causes for immune system dysfunction in obese patients. Therefore, the significant association between CRSwNP and obesity found in this study could be explained by nasal polyps being strongly related to recurrent and severe CRS in most cases ${ }^{30}$ which is possibly due to decreased immune function seen in obesity.

The association between central obesity and CRSwNP was significant after adjusting for various confounding factors, in contrast to CRSsNP, in this study. This difference suggests that mechanisms related to central obesity might impact the pathogenesis of nasal polyps in CRS. The prevalence of central obesity, defined as excessive fat accumulation around the abdomen, is increasing and is associated with elevated mortality risk. ${ }^{32}$ Visceral fat is correlated with elevated production of inflammatory factors, leading to increased metabolic complications. ${ }^{33}$ Studies have reported that the connection between obesity and inflammatory diseases is mediated by oxidative stress and inflammation. ${ }^{32}$ Compared with other fat deposits, visceral fat has more pronounced inflammatory effects, including increased levels of free fatty acids, adipocytokines and inflammatory molecules, all playing critical roles in inflammatory diseases. ${ }^{34}$ Superfluous adiposity in the upper trunk has been reported to be a risk factor for dyslipidaemia, type 2 diabetes, 
hypertension, cardiovascular diseases and hyperinsulinaemia. ${ }^{35}$ The metabolic and endocrine effects of obesity, and the changes in production of hormones including insulin, adipocytokines, insulin-like growth factor-1 and insulin-like growth factor binding protein-3 secreted by adipose tissue have been reported as potential causes for the development of adenomatous polyps and cancer in the colon. ${ }^{36}{ }^{37}$ The mechanism of polypogenesis in the nasal cavity should be further investigated from a metabolic prospective.

We also found that sinonasal symptoms such as olfactory dysfunction and purulent discharge showed a higher prevalence in the central obesity group. This suggests that central obesity might be associated with an increased risk of chronic rhinosinusitis, showing a higher incidence of local sinonasal inflammatory signs. Generally, the mucosa during allergic inflammation is pale and swollen, while it is mostly reddish during acute infections and in overuse of topical nasal sprays. ${ }^{38}$ In our study, pale mucosa, which is more prevalent in allergic rhinitis, showed a higher prevalence in the normal group, consistent with a previous report which showed that obese patients have a higher incidence of non-allergic rhinitis. ${ }^{39}$ Further investigations on the mechanism behind these observations is warranted.

This cross-sectional study is limited by its inability to evaluate the causal relationship between obesity and the CRS phenotypes. In addition, since the KNHANES is based on self-reported questionnaires in reporting parameters on confounding factors, response biases may have occurred.

Besides the confounders used in the multiple regression analysis, psychiatric conditions, ${ }^{40}$ gastro-oesophageal reflux disease, ${ }^{41}$ autoimmune disease ${ }^{9}$ and various environmental exposures ${ }^{42}$ are potential risk factors for CRS. However, these factors were not included as confounders due to unavailability of data. Furthermore, obesity is an important risk factor for asthma in adults, ${ }^{43}$ and the possible correlation between severity of asthma and obesity could not be considered in this analysis. Nevertheless, the present study has notable advantages in that it has evaluated the correlation between CRS phenotypes and general and central obesity using a well-defined representative sample of adults in South Korea. In addition, endoscopic examinations and medical interviews were conducted by trained otolaryngologists, and confounding factors related to the association between CRS and obesity were adjusted for in the statistical analysis.

\section{CONCLUSION}

This study demonstrated a distinct association between CRSwNP and general and central obesity in a large nationwide population sample. Among sinonasal symptoms, the incidences of olfactory dysfunction and purulent discharge were higher in the central obesity group than in the control group. These results suggest a possible role of obesity in the development of CRSwNP, which is mostly refractory to medical treatment and often recurs even after surgery. Further investigations on the mechanism of this correlation is anticipated for elucidating the pathogenesis of CRSwNP.

Author affiliations

${ }^{1}$ Department of Otorhinolaryngology, Yonsei University College of Medicine, Seoul, Korea

${ }^{2}$ Department of Medical Statistics, Yonsei University College of Medicine, Seoul, Korea

${ }^{3}$ Department of Otorhinolaryngology, Imam Abdulrahman Bin Faisal University, Dammam, Saudi Arabia

${ }^{4}$ Department of Otorhinolaryngology, Yonsei University Yongin Severance Hospital, Yongin, Korea

${ }^{5}$ Airway Mucus Institute, Yonsei University College of Medicine, Seoul, Korea ${ }^{6}$ Korea Mouse Sensory Phenotyping Center, Yonsei University College of Medicine, Seoul, Korea

${ }^{7}$ Taste Research Center, Yonsei University College of Medicine, Seoul, Korea

Acknowledgements The authors thank the Biostatistics Collaboration Unit at Yonsei University for providing advice regarding the statistical analysis.

Contributors $\mathrm{J}-\mathrm{SN}$ and $\mathrm{H}-\mathrm{JC}$ designed the study and wrote the manuscript. WAF, $\mathrm{J}$-GH and $\mathrm{H}$-EN contributed to data collection. J-SN, WAF and YHR performed the statistical analysis. J-HY, C-HK and H-JC interpreted the results. All authors read and approved the final manuscript.

Funding This work was supported by the National Research Foundation of Korea (NRF) grant funded by the Korean Government (MSIT) (NRF-2021R1A2C2010811) to H-JC. This work was supported by the National Research Foundation of Korea (NRF) Grant funded by the Korean Government (MSIP) (No. 2016R1A5A2008630). This study was supported by the 'Team Science Award' of Yonsei University College of Medicine (6-2021-0005).

Competing interests None declared.

Patient consent for publication Not required.

Ethics approval This study received approval from the institutional review board (IRB) of the Korean Center for Disease Control and Prevention, with IRB approval numbers 2008-04EXP-01-C, 2009-01C0N-03-2C, 2010-02CON-21-C, 2011-02CON-06-C and 2012-01EXP-01-2C.

Provenance and peer review Not commissioned; externally peer reviewed.

Data availability statement Data are available in a public, open access repository. Extra data can be accessed via the Dryad data repository at http://datadryad.org/ with the doi: 10.5061/dryad.9kd51c5h2.

Open access This is an open access article distributed in accordance with the Creative Commons Attribution Non Commercial (CC BY-NC 4.0) license, which permits others to distribute, remix, adapt, build upon this work non-commercially, and license their derivative works on different terms, provided the original work is properly cited, appropriate credit is given, any changes made indicated, and the use is non-commercial. See: http://creativecommons.org/licenses/by-nc/4.0/.

ORCID iDs

Jae-Sung Nam http://orcid.org/0000-0002-3428-8108

Hyung-Ju Cho http://orcid.org/0000-0002-2851-3225

\section{REFERENCES}

1 NCD Risk Factor Collaboration (NCD-RisC). Worldwide trends in body-mass index, underweight, overweight, and obesity from 1975 to 2016: a pooled analysis of 2416 population-based measurement studies in 128.9 million children, adolescents, and adults. Lancet 2017;390:2627-42.

2 Baffi CW, Winnica DE, Holguin F. Asthma and obesity: mechanisms and clinical implications. Asthma Res Pract 2015;1:1.

3 Costa RM, Neves KB, Tostes RC, et al. Perivascular adipose tissue as a relevant fat depot for cardiovascular risk in obesity. Front Physiol 2018;9:253

4 Cancello R, Clément K. Is obesity an inflammatory illness? role of low-grade inflammation and macrophage infiltration in human white adipose tissue. BJOG 2006;113:1141-7.

5 Kanagalingam S, Shehab SS, Kaminsky DA, et al. Effect of obesity on sinonasal disease in asthma. J Asthma 2018;55:525-31. 
6 Sidell D, Shapiro NL, Bhattacharyya N. Obesity and the risk of chronic rhinosinusitis, allergic rhinitis, and acute otitis media in school-age children. Laryngoscope 2013;123:2360-3.

7 Lee S, Lane AP. Chronic rhinosinusitis as a multifactorial inflammatory disorder. Curr Infect Dis Rep 2011;13:159-68.

8 Kern RC, Conley DB, Walsh W, et al. Perspectives on the etiology of chronic rhinosinusitis: an immune barrier hypothesis. Am J Rhinol 2008;22:549-59.

9 Kashani S, Carr TF, Grammer LC, et al. Clinical characteristics of adults with chronic rhinosinusitis and specific antibody deficiency. $J$ Allergy Clin Immunol Pract 2015;3:236-42.

10 Fokkens WJ, Lund VJ, Mullol J, et al. European position paper on rhinosinusitis and nasal polyps 2012. Rhinol Suppl 2012;23:3.

11 Olze H, Förster U, Zuberbier T, et al. Eosinophilic nasal polyps are a rich source of eotaxin, eotaxin-2 and eotaxin-3. Rhinology 2006;44:145-50.

12 Yao T, Kojima Y, Koyanagi A, et al. Eotaxin-1, -2, and -3 immunoreactivity and protein concentration in the nasal polyps of eosinophilic chronic rhinosinusitis patients. Laryngoscope 2009;119:1053-9.

13 Van Bruaene N, Pérez-Novo CA, Basinski TM, et al. T-Cell regulation in chronic paranasal sinus disease. J Allergy Clin Immunol 2008;121:1435-41.

14 Stevens WW, Ocampo CJ, Berdnikovs S, et al. Cytokines in chronic rhinosinusitis. Role in eosinophilia and Aspirin-exacerbated respiratory disease. Am J Respir Crit Care Med 2015;192:682-94.

15 Deal RT, Kountakis SE. Significance of nasal polyps in chronic rhinosinusitis: symptoms and surgical outcomes. Laryngoscope 2004;114:1932-5.

16 Toros SZ, Bölükbasi S, Naiboğlu B, et al. Comparative outcomes of endoscopic sinus surgery in patients with chronic sinusitis and nasal polyps. Eur Arch Otorhinolaryngol 2007;264:1003-8.

17 Khan A, Huynh TMT, Vandeplas G, et al. The Galen rhinosinusitis cohort: chronic rhinosinusitis with nasal polyps affects health-related quality of life. Rhinology 2019;57:343-51.

18 Balistreri CR, Caruso C, Candore G. The role of adipose tissue and adipokines in obesity-related inflammatory diseases. Mediators Inflamm 2010;2010:802078.

19 Orgel E, Mueske NM, Sposto R, et al. Limitations of body mass index to assess body composition due to sarcopenic obesity during leukemia therapy. Leuk Lymphoma 2018;59:138-45.

$20 \mathrm{Koh} \mathrm{JH}$, Koh SB, Lee MY, et al. Optimal waist circumference cutoff values for metabolic syndrome diagnostic criteria in a Korean rural population. J Korean Med Sci 2010;25:734-7.

21 Fokkens WJ, Lund VJ, Mullol J, et al. Epos 2012: European position paper on rhinosinusitis and nasal polyps 2012. A summary for otorhinolaryngologists. Rhinology 2012:50:1-12.

22 World Health Organization Western Pacific Region. The Asia-Pacific perspective: redefining obesity and its treatment. Geneva: World Health Organization, 2000.

23 Kim MK, Lee WY, Kang JH, et al. 2014 clinical practice guidelines for overweight and obesity in Korea. Endocrinol Metab 2014;29:405-9.

24 S PH L, Kim SM, Kwon HS, et al. Cut-Off points of waist circumference for defining abdominal obesity in the Korean population. Korean J Obes 2006;15:1-9.
25 Christensen RAG, Raiber L, Macpherson AK, et al. The association between obesity and self-reported sinus infection in non-smoking adults: a cross-sectional study. Clin Obes 2016;6:389-94.

26 Kabeya Y, Kato K, Tomita M, et al. Higher body mass index and increased prevalence of paranasal sinus disease. $J$ Epidemiol 2016;26:258-63

27 Antonio-Villa NE, Bello-Chavolla OY, Vargas-Vázquez A, et al. The combination of insulin resistance and visceral adipose tissue estimation improves the performance of metabolic syndrome as a predictor of type 2 diabetes. Diabet Med 2020;37:1192-1201.

28 Greenberg AS, Obin MS. Obesity and the role of adipose tissue in inflammation and metabolism. Am J Clin Nutr 2006;83:461S-5.

29 Scott HA, Gibson PG, Garg ML, et al. Airway inflammation is augmented by obesity and fatty acids in asthma. Eur Respir $J$ 2011;38:594-602.

30 Ghanim H, Aljada A, Hofmeyer D, et al. Circulating mononuclear cells in the obese are in a proinflammatory state. Circulation 2004;110:1564-71.

31 Michalek RD, Gerriets VA, Jacobs SR, et al. Cutting edge: distinct glycolytic and lipid oxidative metabolic programs are essential for effector and regulatory CD4+ T cell subsets. J Immunol 2011;186:3299-303.

32 Marseglia L, Manti S, D'Angelo G, et al. Oxidative stress in obesity: a critical component in human diseases. Int $\mathrm{J} \mathrm{Mol} \mathrm{Sci}$ 2014;16:378-400.

33 Shah RV, Murthy VL, Abbasi SA, et al. Visceral adiposity and the risk of metabolic syndrome across body mass index: the MESA study. JACC Cardiovasc Imaging 2014;7:1221-35.

34 Ritchie SA, Connell JMC. The link between abdominal obesity, metabolic syndrome and cardiovascular disease. Nutr Metab Cardiovasc Dis 2007;17:319-26.

35 Carey VJ, Walters EE, Colditz GA, et al. Body fat distribution and risk of non-insulin-dependent diabetes mellitus in women. The nurses' health study. Am J Epidemiol 1997;145:614-9.

36 Calle EE, Kaaks R, Overweight KR. Overweight, obesity and cancer: epidemiological evidence and proposed mechanisms. Nat Rev Cancer 2004;4:579-91.

37 Pischon T, Nimptsch K. Obesity and risk of cancer: an introductory overview. Recent Results Cancer Res 2016;208:1-15.

38 International Consensus Report on the diagnosis and management of rhinitis. International rhinitis management Working group. Allergy 1994;49:1-34.

39 Han Y-Y, Forno E, Gogna M, et al. Obesity and rhinitis in a nationwide study of children and adults in the United States. J Allergy Clin Immunol 2016;137:1460-5.

40 Schlosser RJ, Storck K, Cortese BM, et al. Depression in chronic rhinosinusitis: a controlled cohort study. Am J Rhinol Allergy 2016:30:128-33.

41 Kim SY, Park B, Lim H, et al. Gastroesophageal reflux disease increases the risk of chronic rhinosinusitis: a nested case-control study using a national sample cohort. Int Forum Allergy Rhinol 2019;9:357-62.

42 Sundaresan AS, Hirsch AG, Storm M, et al. Occupational and environmental risk factors for chronic rhinosinusitis: a systematic review. Int Forum Allergy Rhinol 2015;5:996-1003.

43 Brashier B, Salvi S. Obesity and asthma: physiological perspective. J Allergy 2013;2013:198068. 